\title{
The planning and the design of The Wisdom Campus based on the Internet of Things technology
}

\author{
Xinyue $X U$ \\ Electronics and Information Engineering School, Anhui University, Hefei, China \\ xuxinyuekelly@163.com
}

Keywords: the Internet of Things technology,WIFI,RFID,the Wisdom Campus

\begin{abstract}
The rapid development of Internet of Things (IoT) technology leads the third wave of development of information industry around the world. The development of IoT technology integrates into the campus which arouses a discussion of the wisdom of the campus. Firstly, the article introduces the concept and development status of IoT. Then the article discusses background and significance of the wisdom campus. The article also introduces the architecture and the development direction of the Wisdom Campus based on the Internet of things technology and introduces six systems of the Wisdom Campus respectively. At last, we analyze the development prospects and existing problems of the Wisdom Campus.
\end{abstract}

\section{Introduction}

The concept of the IoT comes from network radio frequency identification systems of the Auto-ID Center proposed by Massachusetts Institute of Technology (MIT) in 1999.

November 17, 2005, in Tunis World Summit on the Information Society (WSIS), the ITU Internet Report 2005: the Internet of Things published by the International Telecommunication Union (ITU) proposed the concept of the Internet of Tings first time. Since then people have a preliminary understanding about the IoT. Many years later, the development of the IoT has been more and more thriving. If we think that the appearance of the computer and the Internet is an important change of information technology, changed the way people lived. The Internet of Things is the third wave of the development of information industry. The Internet of Thing technology based on the Internet technology, through radio frequency identification (RFID) technology, the Smart Sensor technology, the Global Positioning technology, the Embedded System technology and so on. The Internet of Things technology contact people and people, things and things, people and things, complying the intelligent identification, management, positioning, monitoring, and resource sharing.

In recent years, the major developed countries of the world have started the strategic plan about the Internet of Things. In 2004, the Japanese Ministry of Internal Affairs (MIC) proposed u-Japan plan. The strategy sought to connect people and people, things and things, people and things. Japan hope to build an ubiquitous network society that anytime, anywhere, anything, anyone could be connect. In 2006, South Korea proposed "u-Korea" program. The program aims to establish ubiquitous society, building intelligent network (such as IPv6, USN) and a variety of new applications (such as DMB, Telematics, RFID) in people's living environment. So that people can enjoy Intelligent Technology Services anytime, anywhere. In 2009 the European Commission published a European plan of the Internet of Things. Plan depicts the prospect of the IoT technology, and proposed that EU governments should strengthen the management of the IoT to promote the 
development of things. January 28, 2009, after Obama became US president, he held a "round table" with US business leaders. As one of only two representatives, IBM CEO Sam Palmisano put forward the "wisdom of the Earth" concept for the first time, and proposed new government investment in a new generation of intelligent infrastructure. That year, the United States toke the new energy and the IoT as the two keys to revive the economy. August 2009, Premier Wen Jiabao put forward the "Experience China" concept, making the research and application development of the Internet of Things into a peak. In the same year, the Internet of Thing are officially listed as one of the five emerging strategic industries, wrote into "The Government Work Report." The internet of Things technology in China's development has been of great concern degree than other countries.

\section{The background of the Wisdom Campus}

With the progress of modern technology, various industries have raised a wave of information technology. School education also began to change for the network campus and digital campus. With the proposed of the Smarter Planet and Smart City concept, the development of the Information Times has been more and more rapid. College as an important medium of information services and knowledge is bound to join this revolution. The concept of the Wisdom Campus was proposed from Zhejiang University in 2010. Its proposal aims to create ubiquitous network learning, Innovative network research, transparent and efficient school management, rich college cultural life, convenient and comfortable campus life. This proposal has aroused discussion and responses positively in the field of education, aimed to create an platform could have mutual communication and mutual perception between teachers and students.

The Wisdom Campus can offer comfortable learning environmental for teachers and students and protect the safety of the campus. Wisdom campus can be seen as an upgraded version of the network campus. Through IoT technology connected all kinds of items in College LAN to the Internet, building infrastructure platform with consistency, data sharing platform with consistency and school information service platform. At present, the wisdom of campus construction is still in the initial stage in China, making progress in practice, striving to build high-performance, low-cost, multi-angle wisdom campus environment.

\section{The Structure of wisdom Campus System}

The Wisdom Campus System based on the Internet of Things technology, using EPC, RFID, sensors and other technology to set fee system, monitoring system, laboratory management system, education management system in a same management platform for sharing, organizing and summarizing information. The Wisdom Campus System changed the situation of resources complex and management difficult in the past, achieving intelligence service and management. Some foreign schools have started ahead of us in the research of the Wisdom Campus System. University of Pennsylvania in the United States has made a contribution to the campus card, the campus card integrated almost all services on campus, including student ID cards, building access control, library services, and also integrates with the phone card, bank card, after graduation it can still be used as discount card. In addition, the University of California established a scientific decision analysis system, to achieve more careful management and services, through perceiving student's real-time information. However, the Wisdom Campus construction started late, it has also attracted great concern from all aspects of society. The Wisdom Campus System can be divided into the Intelligent Vehicle Access Control Systems, the Intelligent Library Management System, the Intelligent Tutoring Management Systems, the Intelligent Consumption Management Systems, the Smart 
Security Systems, the Intelligent Lab Management System six parts. Although each of t six systems is an independent system, the information could be concentrated together by network technology to achieve campus resource sharing. The Wisdom Campus System can also sense the environment through intelligent technology, providing an interface for the inside and outside. The system not only safeguards campus safety, but also strengthened ties with the outside world. Overall, the Wisdom Campus built on teaching, research, administration and campus life as one of the wisdom of working and learning environment, based on IoT technology, through collaboration with an open interactive intelligent integrated information service platform.

The Intelligent Vehicle Management System. The Intelligent Vehicle Management System (IVMS) can identify different cars and charge. The IVMS obtains licenses from vehicle entered or out of the campus, through the License Plate Recognition (LPR) technology. System will analyze and monitoring vehicle information, which will be delivered to the database of School Management System. Vehicles of registered teachers will be permitted to entry, but social vehicles will be monitored, managed and charged. The appearance of the Intelligent Vehicle Management System changes the status of inefficiency within the original campus, greatly reducing the waste of human and material resources. The IVMS not only improves the efficiency of vehicle access information collection, but also brings convenient and standardized management of the school. All information of vehicles entered and left is sent to the Campus Information Management Platform over the network, and then delivered to the Vehicle Management System in each exit, improving management efficiency and security. Application of campus information platform database and network technology can also statistics the real-time number of cars, speed and other information at the school gate, providing first-hand information to handle emergency situations.

The Intelligent Library System. The Intelligent Library System is based on Radio Frequency Identification technology (RFID) and multifunctional management system of sensor network. System records location and lending information of books, through RFID tags for each book within the library. System changed the way of making handmade paper label and entering book information, greatly reducing the waste of human resources, and library management will become more convenient. People Inquire the location information of books through the computer, and then find the location of books according mobile phone WIFI positioning system, saving a lot of time. Library use intelligent platform, which set fault analysis, energy management, equipment monitoring, property management together and base on IoT technology architecture. The platform can realize intelligent control and unified management for the equipment, environment, lighting, security and other facilities. The Intelligent Library System can adjust the central air conditioning automatically within the library, according to the indoor temperature and humidity. The system not only saves electricity, but also provides readers a more comfortable environment. Library Lighting System uses intelligent control technology, and arrange a large number of light sensors to acquit real-time brightness information of each point in the library. The light will be turned on or off automatically according to the current brightness. According to outdoor light intensity, system will also adjust brightness of the lights and curtains opening degree automatically. Smoke sensor within the library can be combined with video surveillance to monitor the fire. In case of fire, it will notify administrator immediately. If administrator does not answer, it will alarm to the fire center directly. Before firefighters arrived, the system can control fire-fighting equipment by video surveillance and smoke sensor information, opening fire extinguishers and sprinkle to Extinguishing fire in the shortest time. The Intelligent Library System not only improves the working efficiency, but also brings great security indemnification for protection of rare books and personal safety of readers. 
The Intelligent Tutoring Management System. The Intelligent Tutoring Management System can identify RFID tag within the student campus card, and record the student's school situation. Student swipe card into the classroom before each class, attendance information will automatically transmit to the database. According to analysis of the student's curriculum, attendance results will be transferred to teacher sign-in system, so teachers no longer need to waste time to call the roll each lesson. The Intelligent Tutoring Management System also recorded for each classroom's status, marking empty classrooms to facilitate student self-study and avoiding the students to find empty classroom layer upon layer.

The Intelligent Consumption Management System. The Intelligent Consumption Management System connects students' campus card and bank card by network, recording consumer information in the canteen, supermarket and bathroom into database to facilitate to inquiry in the future. According to the students' consumption, system will update database of school information platform. Recorded consumption of teachers and students, in order to adjust the price of goods on campus.

The Intelligent Security System. The Intelligent Security System can monitor and manage social people and social vehicles entered campus. If system finds suspicious persons, through the campus surveillance cameras around the campus, it will inform the security department directly. There are many warning lines around the campus, if someone touches, the Intelligent Security System will targeted rapidly by positioning technology, informing security to search.

The Intelligent Laboratory Management System. The Intelligent Laboratory Management System strictly controls the admittance of the laboratory by identifying campus card and fingerprint. System can enter campus card information from students and teachers, who have admittance of the laboratory, opening admittance for different people in different laboratories, to facilitate students to experiment on the weekend. The laboratory's temperature and humidity can be monitored by the Intelligent Laboratory Management System, to protect experimental equipment and standardize experiment.

\section{The problems of the development of wisdom campus}

The IoT industry is still in infancy stage in our country, without a unified industry standard. At present, a lot of IoT products are imported from abroad, so the cost is too high. They are not suitable for large-scale use. If we want to build the Wisdom Campus base on the IoT, campus-wide wireless network coverage is a very important thing. Although our current level of technology is not enough to realize the wisdom of the campus, it is believed that the Wisdom Campus must be built successful in China through the efforts of the researchers.

\section{References}

[1] LiuHaotian. Strategy of Wisdom College Campus Construction[J]. Chinese Management Information. 2015,07:206-207.

[2] WuYanyu, LiuHuan, RenYouqun. New Stage of University Campus wisdom: "Internet +" Campus[J]. Journal of Distance Education. 2015,04:8-13.

[3] LiZhigang. Discussion on the IOT wisdom based on institution-building campus services[J]. Electronics and Software Engineering, 2015 (16): 15-16.

[4] DengXiaoxu. http://www.cnki.net/kcms/detail/10.1108.TP.20160513.1518.008.html 
[5] WangQing, Wang Jianhua. A probe into development of IOT and higher vocational education[J]. Journal of Nantong Vocational \& Technical Shipping College. 2010 (3):98-101. 